\title{
Women's modern contraceptive use in sub-Saharan Africa: does men's involvement matter?
}

\author{
Shireen Assaf ${ }^{1}$, Lwendo Moonzwe Davis ${ }^{1}$ \\ ${ }^{1}$ ICF, Rockville, Maryland, USA \\ Keywords: global health \\ https://doi.org/10.29392/joghr.3.e2019013
}

\section{Journal of Global Health Reports}

Vol. 3, 2019

\begin{abstract}
Background
Men's involvement in family planning can play an important role in improving the use of modern contraceptives. Several studies have shown that family planning interventions that involve men have resulted in positive outcomes. However, these studies are mainly case-control studies with a specific focus area. This paper used data from men's responses in Demographic and Health Surveys (DHS) in 27 sub-Saharan African countries to study whether there is an association between men's involvement and modern contraceptive use using nationally represented cross-sectional data.
\end{abstract}

\section{Methods}

For the analysis, data on men's involvement was linked with information from women's survey responses on their modern contraceptive use. The objective was to learn whether men's involvement, defined as having correct knowledge, positive attitudes, and supportive behaviors in family planning has an association increased modern contraceptive use in their partners/wives. Women's and men's education level was also examined. Adjusted logistic regression models for modern contraceptive use were fit for each main independent variable along with control variables.

\section{Results}

Although in general few countries exhibited significant findings, the analysis found that the most significant findings were for the behavior of men discussing family planning with a health care worker. In addition, countries that had a modern contraceptive rate below or equal to $20 \%$ had more significant findings than countries that had a modern contraceptive rate of above $20 \%$.

\section{Conclusions}

Men's behavior was a stronger predictor of women's contraceptive use compared to their knowledge or attitudes. Findings suggest that interventions in countries will low contraceptive could be more effective. The main limitation of the analysis was the cross-sectional nature of the data.

For several decades, advocates for family planning have promoted the importance of male involvement as a way to facilitate uptake of modern contraceptive use. ${ }^{1,2}$ In many parts of the world, men play a central role in decision-making regarding family planning and the use of contraceptives. ${ }^{3,4}$ Although engaging men in health care for women is not a universal strategy, several maternal health interventions have advocated for male involvement as a means to improve outcomes for family planning and women's overall sexual and reproductive. ${ }^{5,6}$ The impact of men's involvement in family planning and the use of modern contraceptive methods is directly linked to men's knowledge and education, their attitudes, and their behaviors. 7,8

\section{MEN'S KNOWLEDGE}

Studies have shown that interventions to educate men about family planning and improve their knowledge of contraceptive methods are successful in increasing the use of modern contraceptive methods among couples.8,9 Men's knowledge of contraception is linked to their life course and to socioeconomic factors. ${ }^{10,11}$ For example, a study across 18 countries in Africa, Asia, and Latin America and the Caribbean found that men with no children and never-married men had the lowest levels of contraceptive knowledge, while in most of the countries men's contraceptive knowledge was also positively and significantly associated with their level of education; it was highest among men age $35-45.11$ 
An increase in knowledge related to family planning has been associated with uptake of contraceptive use across several countries. Men in Southeast Nigeria that were aware of female contraception were more likely to have spouses that wanted to use contraception. ${ }^{12}$ The Malawi Motivator Project demonstrated that contraceptive uptake among couples increase for the men who were educated through their peers about the importance of using contraceptives. ${ }^{8}$ A study in Ethiopia also found that involving men in discussions of family planning with their wives made a significant difference in modern contraceptive use; twice as many members of the intervention group were using a modern contraceptive method compared with the control group. ${ }^{13}$ In Kenya, Nigeria and Senegal the Urban Reproductive Health Initiative program undertook demand-generation activities using mass media, interpersonal communication and branding of program material to improve knowledge of contraceptive methods, foster family planning discussions and increase social approval for family planning. ${ }^{9}$ In Kenya, interpersonal communication through community outreach events was associated with greater use of modern contraceptives. In Nigeria, exposure to slogans that promoted seeking information about family planning, and in Senegal exposure to radio advertisements promoting family planning were associated with greater modern contraceptive use. ${ }^{9}$ Although men's knowledge about family planning is an important factor in increasing the use of modern contraceptives between them and their partners, men's attitudes and perceptions about family planning is another critical factor.

\section{MEN'S ATTITUDES AND PERCEPTIONS}

Changing men's attitudes and perceptions helps to achieve better family planning outcomes as knowledge alone may not be enough. For example, interviews conducted among the Hausa people in Northern Nigeria showed that most men were aware of contraceptive methods (nearly twothirds reported knowing at least one method), but $85 \%$ of men were not willing to allow their spouses to use family planning, even when they were not able financially to take care of their current number of children. ${ }^{10}$ The desire to have multiple children is often noted as a primary reason for limiting the use of modern contraceptives. Religious beliefs that discouraged the use of contraceptives to prevent childbearing and the view of children as desirable were why some men in Northern Nigeria had negative attitudes and perceptions about the use of contraceptives. ${ }^{10}$ Conversely, messages from religious leaders can also have a positive impact on family planning. In Senegal, hearing a religious leader speak favorably about family planning was associated with modern contraceptive method use. ${ }^{9}$

Negative perceptions or misconceptions about the impact of modern contraceptive use was a hindrance to supporting family planning. ${ }^{14,15}$ As noted by some men in Uganda, other negative aspects of women's contraceptive use include reduced sexual pleasure for women, increased infertility risks, and fear of engagement in extramarital sexual relationships due to a belief that women who use contraception might become promiscuous since they could avoid becoming pregnant. ${ }^{14}$ A study based on data from 58
Demographic and Health Surveys (DHS) in 18 countries in Africa, Asia, and Latin America and the Caribbean found that most men in most of the countries agreed that contraceptive use is associated with promiscuity, even though more than half of respondents disagreed with the statement that "contraception is a woman's business". 11 Gendertransformative approaches-that is, interventions or programs that promote understanding and challenge social norms and attitudes that perpetuate inequalities between men and women-have proven effective in changing gender inequalities and improving health-related behaviors. ${ }^{16-18}$ Such approaches maybe useful in facilitating changes in attitudes and perceptions that then can lead to behavioral change.

\section{MEN'S BEHAVIOR}

An assessment of a gender-transformative intervention for couples on several behavioral and health-related outcomes that were influenced by gender norms and power relations found that couples that participated in the intervention had greater use of modern contraception. ${ }^{16}$ The Malawi Motivator Project, provides another example of how interventions focused on behavioral change, through approaches like the information-motivation-behavior (IMB) model have resulted in succesful outcomes. In its application of the IMB model, married men who were given information about modern family planning methods were motivated to act on this information and to follow better practices and behavior skills related to family planning. ${ }^{8}$ While before the intervention all participants in both the intervention (the Malawi Motivator Project) and the control group reported not using contraceptives, after the intervention $78 \%$ in the intervention group reported using family planning methods compared with $59 \%$ in the control group. Another study conducted in Ethiopia also found that men who participated in a family planning intervention focused on education and participation in community gatherings for couples were more likely to be actively involved in family planning compared with men who did not participate. ${ }^{19}$ Men's behaviors, as reflected by active participation in interventions promoting family planning often result in an increase in the use of modern contraceptive methods. Further, interventions that focused on three elements of knowledge, attitudes and behavior showed promising outcomes related to uptake of modern contraceptive use.

This paper examines men's knowledge, attitudes, and behaviors (representing men's involvement) toward family planning based on men's responses to questions asked in DHS in these areas. We linked these data with data on modern contraceptive use in the men's partners. The objective of the analysis is to study whether there is an association between men's involvement in family planning and modern contraceptive use by their wives/partners after controlling for socio-demographic variables. The hypothesis is that a high level of knowledge, nondiscriminatory and positive attitudes, and positive behaviors among men about family planning would be associated with a higher modern contraceptive use in their partners. 
Table 1. Sample sizes and number of women and men interviewed in the surveys used in the analysis

\begin{tabular}{|c|c|c|c|c|}
\hline Country & Survey year & $\begin{array}{l}\text { Households } \\
\text { interviewed }\end{array}$ & $\begin{array}{l}\text { Women aged 15-49 } \\
\text { interviewed }\end{array}$ & Men interviewed* \\
\hline Angola & $2015-16$ & 16,109 & 14,379 & $5,684 b$ \\
\hline Burkina Faso & 2010 & 14,424 & 17,087 & $7,307 c$ \\
\hline Benin & 2011-12 & 17,422 & 16,599 & $5,180 d$ \\
\hline Burundi & 2010 & 8,596 & 9,389 & $4,280 c$ \\
\hline Chad & 2014-15 & 17,233 & 17,719 & $5,248 c$ \\
\hline Comoros & 2012 & 4,482 & 5,329 & $2,167 c$ \\
\hline Congo Democratic Republic & 2013-14 & 18,171 & 18,827 & $8,656 c$ \\
\hline Côte d'Ivoire & 2011-12 & 9,686 & 10,060 & $5,135 c$ \\
\hline Ethiopia & 2016 & 16,650 & 15,683 & $12,688 \mathrm{c}$ \\
\hline Gambia & 2013 & 6,217 & 10,233 & $3,821 c$ \\
\hline Ghana & 2014 & 11,835 & 9,396 & $4,388 c$ \\
\hline Kenya & 2014 & 17,409 & 14,741 & $12,819 b$ \\
\hline Lesotho & 2014 & 9,402 & 6,621 & $2,931 c$ \\
\hline Liberia & 2013 & 9,333 & 9,239 & $4,118 a$ \\
\hline Malawi & $2015-16$ & 26,361 & 24,562 & $7,478 b$ \\
\hline Mali & $2012-13$ & 10,105 & 10,424 & $3,816 a$ \\
\hline Mozambique & 2011 & 13,919 & 13,745 & $4,035 d$ \\
\hline Namibia & 2013 & 9,849 & 9,176 & $4,481 d$ \\
\hline Nigeria & 2013 & 38,522 & 38,948 & $17,359 a$ \\
\hline Rwanda & 2014-15 & 12,699 & 13,497 & $6,217 c$ \\
\hline Senegal & 2016 & 4,437 & 8,865 & $3,527 c$ \\
\hline Sierra Leone & 2013 & 12,629 & 16,658 & $7,262 a$ \\
\hline Tanzania & $2015-16$ & 12,563 & 13,266 & $3,514 a$ \\
\hline Togo & 2013-14 & 9,549 & 9,480 & $4,476 c$ \\
\hline Uganda & 2016 & 19,588 & 18,506 & $5,336 \mathrm{~b}$ \\
\hline Zambia & 2013-14 & 15,920 & 16,411 & $14,773 c$ \\
\hline Zimbabwe & 2015 & 10,534 & 9,955 & $8,396 b$ \\
\hline
\end{tabular}

*Ages of men interviewed: a - age 15-49; b - age 15-54; c - age 15-59; d - age 15-64.

\section{METHODS}

DATA

The analysis uses data from the most recent Demographic and Health Survey in 27 sub-Saharan African countries, as shown in Table 1. Countries from sub-Saharan Africa were selected for the analysis if they included all of the DHS survey questions on men's involvement, as described below for the independent variables, and if they had a recent DHS survey that was completed between 2010 and 2016.

\section{OUTCOME VARIABLE}

The outcome of interest is modern contraceptive prevalence rate (mCPR) among women age 15-49 currently in a union. Modern contraceptive methods include pills, intrauterine device (IUD), injections, implants, diaphragm, female and male condoms, female and male sterilization, foam or jelly, and the lactational amenorrhea method (LAM). The mCPR may also include other modern contraceptive methods that are country-specific or less common but were reported by the respondent and identified in the datasets as modern methods.

\section{INDEPENDENT VARIABLES}

The main independent variables of interest are derived from questions in the DHS Men's Questionnaire that ask about the respondent's involvement in different aspects of their partner's health. These questions can be grouped into three domains: men's knowledge, men's attitude, and men's behavior. The variables derived from these questions were coded in the positive direction, i.e., correct knowledge, positive attitudes, and positive behaviors. In addition to examining men's correct knowledge, their education level will also be examined (have secondary or more education level versus none or primary level). The effect of the women's education level as a comparison was also examined. The definitions below describe the knowledge, attitude, and behavior related variables obtained from the men's questionnaire.

Knowledge: Men who have correct knowledge of a woman's fertile period. To have correct knowledge, the respondent should give the answer of halfway between two menstrual peri- 
ods. The other options for this question are: just before her period begins, during her period, right after her period has ended, other, and don't know. No other knowledge question related to family planning or reproductive health was found in the men's questionnaire.

Attitude: Men's attitudes related to contraception were measured using two questions which ask men if they agree with the following statements:

1. Contraception is a woman's business and a man should not have to worry about it.

2. Women who use contraception may become promiscuous.

The two attitude variables were coded in the positive direction to indicate men who do not agree with each of these statements.

Behavior: Men who stated that they discussed family planning with a health worker in the last few months. This is considered as a behavior variable, not a knowledge variable, because it measures the act of discussing with the health worker and not the man's level of knowledge.

\section{CONTROL VARIABLES}

The control variables used in the regression include men's age (continuous variable), men's education (none and primary, secondary and above), women's education (none and primary, secondary and above), place of residence (urban or rural), and wealth quintile (lowest, second, middle, fourth, highest). Men's age was varied depending on the survey (see Table 1). The wife's age was highly correlated with her husband's age and was therefore not included in the regression models. No other variables were found to be highly correlated.

\section{ANALYSIS}

Men and women interviewed in the DHS survey must declare each other as partners to be included in this analysis. This was performed by using an identification code in the data files that links women and their husbands. For men who had multiple wives, one wife was randomly selected. The unit of analysis is therefore the women.

Adjusted logistic regressions were fit for women's modern contraceptive use and each main independent variable representing men's knowledge, attitudes, and behavior separately. All the models were adjusted for the control variables. To study the effect of men's and women's education, a full model was fit with all the independent variables and controls.

The logistic regressions accounted for the DHS sampling design and stratification. Stata 15 (StataCorp, College Station TX, USA) was used for all the analysis.

\section{RESULTS}

The percentage of women using a modern contraceptive method varied significantly across the 27 countries. As Figure 1 shows, the percentage of women age 15-59 in a union currently using a modern contraceptive method ranged from $69 \%$ in Zimbabwe to $7 \%$ in Chad (Table S1 in Online
Supplementary Document(Online Supplementary Document)). Twelve countries had a mCPR higher than $20 \%$ (Group 1) and 15 countries had a mCPR less than 20\% (Group 2). This grouping is used to summarize the results in Figure 6.

Table 2 summarizes the results from the logistic regression of modern contraceptive use by each of the main independent variables. In general we can see there are not many significant findings, however men's behavior of speaking with a health worker about family planning was significant in the largest number of countries compared to the remaining men's involvement variables. The results from the table are summarized in Figure $\underline{2}, \underline{3}, \underline{4}$ and $\underline{5}$ and a summary is provided in Figure 6. The percentages of main independent variables for all the countries in the analysis is found in Table S2 of the Online Supplementary Document(Online Supplementary Document).

Figure 2 summaries the results from the logistic regression of modern contraceptive use by men's and women's education level. Only five countries had significant odds ratios for increased women's modern contraceptive use if their partners had secondary or above level of education compared to women with partners with no or primary level education. Figure 2, panel a shows that these five countries were Burkina Faso, Chad, Ghana, Liberia, and Nigeria. Many more countries were found to have significant odds ratios for women's education level. Figure 2 , panel b shows that in ten countries women with secondary or higher level of education had higher odds of using a modern contraception compared to women with no or primary level of education. In Malawi the odds was in the opposite of the expected direction with women with secondary or higher level of education having lower odds of modern contraceptive use compared to women with no or primary level of education.

Figure 3 shows that only in Sierra Leone did women with partners that had correct knowledge of a woman's fertile period had significantly higher odds of modern contraceptive use compared with women with partners that have incorrect knowledge. The odds ratio was also significant for Namibia, but in the opposite of the expected direction. The significance in both these countries was marginal $(P<0.05)$ as shown in Table 2 .

Figure 4 shows the adjusted odds ratios for women's modern contraceptive use according to men's attitudes toward women using contraceptive methods. In Figure 4, panel a we see that in Angola, Benin, Nigeria, and Togo, women with partners who did not agree that contraceptive use was only women's business had a greater likelihood of modern contraceptive use compared with women with partners who agreed. Figure 4 , panel b shows that in seven countries - Burkina Faso, Burundi, Kenya, Nigeria, Senegal, Zambia, and Zimbabwe - women with partners who did not agree that women who used contraception might become promiscuous had a greater likelihood of modern contraceptive use compared with women with partners who agreed.

The last variable to be examined is men's behavior of discussing family planning with a health worker, the results of which are summarized in Figure 5 . In Figure 5 we see that in 12 countries women with partners who recently discussed family planning with a health worker were significantly more likely use a modern contraceptive method com- 
Table 2. Adjusted odds ratios with $95 \%$ confidence intervals for women's modern contraceptive use by the main independent variables

\begin{tabular}{|c|c|c|c|c|c|c|c|c|c|c|c|c|c|}
\hline \multirow[b]{3}{*}{ Country } & \multirow[b]{3}{*}{ Survey year } & \multicolumn{4}{|c|}{ Education } & \multirow{2}{*}{\multicolumn{2}{|c|}{$\begin{array}{l}\text { Knowledge } \\
\text { Correct } \\
\text { knowledge of } \\
\text { fertile period } \\
\text { versus incorrect }\end{array}$}} & \multicolumn{4}{|c|}{ Attitude } & \multirow{2}{*}{\multicolumn{2}{|c|}{$\begin{array}{c}\text { Behavior } \\
\text { Discussed family planning } \\
\text { with health worker in the } \\
\text { last few months versus did } \\
\text { not discuss }\end{array}$}} \\
\hline & & \multicolumn{2}{|c|}{$\begin{array}{l}\text { Men's secondary } \\
\text { or more versus } \\
\text { none or primary }\end{array}$} & \multicolumn{2}{|c|}{$\begin{array}{l}\text { Women's } \\
\text { secondary or more } \\
\text { versus none or } \\
\text { primary }\end{array}$} & & & \multicolumn{2}{|c|}{$\begin{array}{l}\text { Does not agree that } \\
\text { contraception is only } \\
\text { a women's business } \\
\text { versus agrees }\end{array}$} & \multicolumn{2}{|c|}{$\begin{array}{l}\text { Does not agree that } \\
\text { women who use } \\
\text { contraception become } \\
\text { promiscuous versus } \\
\text { agrees }\end{array}$} & & \\
\hline & & AOR & $95 \% \mathrm{Cl}$ & AOR & $95 \% \mathrm{Cl}$ & AOR & $95 \% \mathrm{Cl}$ & AOR & $95 \% \mathrm{Cl}$ & AOR & $95 \% \mathrm{Cl}$ & AOR & $95 \% \mathrm{Cl}$ \\
\hline Angola & $2015-16$ & 1.2 & $0.7,2.3$ & $2.4^{* *}$ & $1.4,4.2$ & 0.9 & $0.3,2.4$ & $1.6^{*}$ & $1.0,2.4$ & 0.9 & $0.5,1.4$ & 1.1 & $0.7,1.9$ \\
\hline Benin & 2011-12 & 0.9 & $0.6,1.4$ & 1.5 & $0.9,2.6$ & 1.2 & $0.9,1.7$ & $1.8^{*}$ & $1.1,2.9$ & 1.4 & $1.0,1.9$ & 1.0 & $0.6,1.9$ \\
\hline Burkina Faso & 2010 & $1.5^{*}$ & $1.1,2.2$ & $1.5^{*}$ & $1,2.1$ & 1.1 & $0.9,1.4$ & 1.0 & $0.7,1.4$ & $1.3^{*}$ & $1.0,1.6$ & $1.5^{* * *}$ & $1.2,1.9$ \\
\hline Burundi & 2010 & 1.0 & $0.6,1.6$ & $1.9^{*}$ & $1.2,3.2$ & 1.0 & $0.7,1.3$ & 1.3 & $0.7,2.6$ & $1.3^{*}$ & $1.0,1.8$ & $1.4^{*}$ & $1.0,2.0$ \\
\hline Chad & 2014-15 & $3.6^{* * *}$ & $1.9,7.1$ & 1.3 & $0.7,2.4$ & 0.8 & $0.5,1.3$ & 0.6 & $0.4,1.0$ & 0.7 & $0.4,1.1$ & $2.7^{* * *}$ & $1.6,4.6$ \\
\hline Comoros & 2012 & 0.9 & $0.5,1.4$ & 1.1 & $0.7,1.8$ & 0.9 & $0.6,1.5$ & 0.8 & $0.5,1.3$ & 1.2 & $0.8,1.8$ & $2.0^{* *}$ & $1.2,3.3$ \\
\hline $\begin{array}{l}\text { Congo } \\
\text { Democratic } \\
\text { Republic }\end{array}$ & 2013-14 & 1.2 & $0.6,2.3$ & $1.5^{*}$ & $1,2.2$ & 1.0 & $0.7,1.4$ & 1.0 & $0.7,1.5$ & 1.2 & $0.8,1.8$ & $1.8^{* *}$ & $1.2,2.9$ \\
\hline Côte d'Ivoire & 2011-12 & 1.3 & $0.8,2$ & 1.1 & $0.6,2.2$ & 0.9 & $0.6,1.5$ & 1.2 & $0.8,1.7$ & 1.2 & $0.8,1.7$ & $2.3^{*}$ & $1.2,4.6$ \\
\hline Ethiopia & 2016 & 1.0 & $0.8,1.3$ & 1.1 & $0.8,1.6$ & 1.1 & $0.9,1.3$ & 0.9 & $0.7,1.2$ & 1.0 & $0.8,1.4$ & 1.2 & $1.0,1.5$ \\
\hline Gambia & 2013 & 1.7 & $1,2.9$ & $2.0^{*}$ & $1.1,3.7$ & 0.9 & $0.4,2.1$ & 1.1 & $0.5,2.2$ & 1.6 & $0.9,2.8$ & 0.9 & $0.4,1.7$ \\
\hline Ghana & 2014 & $1.5^{*}$ & $1.1,2$ & 1.1 & $0.8,1.5$ & 0.8 & $0.6,1.1$ & 0.8 & $0.5,1.1$ & 1.2 & $0.9,1.8$ & $1.8^{* *}$ & $1.2,2.9$ \\
\hline Kenya & 2014 & 1.0 & $0.8,1.2$ & 1.1 & $0.9,1.3$ & 0.9 & $0.7,1.2$ & 0.9 & $0.7,1.1$ & $1.3^{* * *}$ & $1.1,1.6$ & 1.0 & $0.8,1.3$ \\
\hline Lesotho & 2014 & 1.1 & $0.7,1.8$ & $1.9^{* * *}$ & $1.3,2.7$ & 1.2 & $0.7,1.8$ & 1.0 & $0.7,1.4$ & 1.1 & $0.8,1.6$ & 1.7 & $0.9,3.3$ \\
\hline Liberia & 2013 & 1.2 & $0.8,1.8$ & $1.9^{* *}$ & $1.2,2.9$ & 1.0 & $0.4,2.6$ & 0.9 & $0.6,1.5$ & 1.0 & $0.7,1.6$ & $1.6^{*}$ & $1.1,2.3$ \\
\hline Malawi & $2015-16$ & $1.3^{*}$ & $1.1,1.6$ & $0.7^{* *}$ & $0.6,0.9$ & 1.1 & $0.8,1.4$ & 1.1 & $1.0,1.3$ & 1.1 & $0.9,1.3$ & 1.1 & $0.9,1.3$ \\
\hline Mali & $2012-13$ & 1.0 & $0.6,1.7$ & 1.5 & $0.9,2.4$ & 1.1 & $0.8,1.6$ & 0.9 & $0.6,1.3$ & 1.0 & $0.8,1.4$ & 0.8 & $0.5,1.3$ \\
\hline Mozambique & 2011 & 1.4 & $1,2.1$ & $2.1^{* *}$ & $1.3,3.3$ & 0.5 & $0.2,1.1$ & 1.3 & $0.9,2.1$ & 0.8 & $0.5,1.2$ & 1.3 & $0.8,2.3$ \\
\hline Namibia & 2013 & 1.3 & $0.9,1.7$ & $2.1^{* * *}$ & $1.5,3$ & $0.4^{*}$ & $0.2,0.9$ & 0.9 & $0.6,1.3$ & 0.8 & $0.6,1.1$ & 0.7 & $0.4,1.2$ \\
\hline Nigeria & 2013 & $1.5^{* *}$ & $1.2,1.9$ & $1.6^{* * *}$ & $1.2,2.1$ & 0.9 & $0.7,1.3$ & $1.4^{* *}$ & $1.1,1.9$ & $1.4^{* *}$ & $1.1,1.7$ & 1.2 & $0.9,1.5$ \\
\hline Rwanda & 2014-15 & 1.1 & $0.8,1.5$ & 0.9 & $0.7,1.2$ & 0.9 & $0.7,1.1$ & 0.9 & $0.6,1.3$ & 1.3 & $0.9,2.0$ & $1.2^{*}$ & $1.0,1.3$ \\
\hline Senegal & 2016 & 1.2 & $0.8,1.9$ & 1.2 & $0.7,2.2$ & 0.9 & $0.4,1.9$ & 1.8 & $1.0,3.3$ & $1.6^{*}$ & $1.0,2.4$ & 0.8 & $0.5,1.4$ \\
\hline Sierra Leone & 2013 & 1.2 & $0.9,1.6$ & 1.1 & $0.8,1.5$ & $1.3^{*}$ & $1.0,1.8$ & 1.0 & $0.8,1.3$ & 1.0 & $0.8,1.3$ & 1.0 & $0.7,1.3$ \\
\hline Tanzania & $2015-16$ & 0.9 & $0.6,1.4$ & 0.9 & $0.6,1.5$ & 1.2 & $0.8,1.8$ & 1.1 & $0.8,1.4$ & 1.1 & $0.8,1.4$ & 1.1 & $0.7,1.5$ \\
\hline
\end{tabular}




\begin{tabular}{|c|c|c|c|c|c|c|c|c|c|c|c|c|c|}
\hline \multirow[b]{3}{*}{ Togo } & \multirow[b]{3}{*}{ 2013-14 } & \multicolumn{4}{|c|}{ Education } & \multirow{2}{*}{\multicolumn{2}{|c|}{$\begin{array}{l}\text { Knowledge } \\
\text { Correct } \\
\text { knowledge of } \\
\text { fertile period } \\
\text { versus incorrect }\end{array}$}} & \multicolumn{4}{|c|}{ Attitude } & \multirow{2}{*}{\multicolumn{2}{|c|}{$\begin{array}{c}\text { Behavior } \\
\text { Discussed family planning } \\
\text { with health worker in the } \\
\text { last few months versus did } \\
\text { not discuss }\end{array}$}} \\
\hline & & \multicolumn{2}{|c|}{$\begin{array}{l}\text { Men's secondary } \\
\text { or more versus } \\
\text { none or primary }\end{array}$} & \multicolumn{2}{|c|}{$\begin{array}{l}\text { Women's } \\
\text { secondary or more } \\
\text { versus none or } \\
\text { primary }\end{array}$} & & & \multicolumn{2}{|c|}{$\begin{array}{l}\text { Does not agree that } \\
\text { contraception is only } \\
\text { a women's business } \\
\text { versus agrees }\end{array}$} & \multicolumn{2}{|c|}{$\begin{array}{l}\text { Does not agree that } \\
\text { women who use } \\
\text { contraception become } \\
\text { promiscuous versus } \\
\text { agrees }\end{array}$} & & \\
\hline & & 1.1 & $0.8,1.5$ & 1.0 & $0.7,1.4$ & 0.9 & $0.7,1.2$ & $1.8^{*}$ & $1.1,2.7$ & 1.3 & $1.0,1.7$ & $2.0^{* * *}$ & $1.5,2.8$ \\
\hline Uganda & 2016 & 1.0 & $0.8,1.3$ & 1.1 & $0.8,1.4$ & 1.0 & $0.7,1.3$ & 1.0 & $0.8,1.3$ & 1.2 & $0.9,1.4$ & 1.1 & $0.9,1.4$ \\
\hline Zambia & 2013-14 & 1.1 & $0.9,1.2$ & 1.1 & $1,1.3$ & 1.0 & $0.8,1.1$ & 1.0 & $0.9,1.2$ & $1.2^{*}$ & $1.0,1.3$ & $1.2^{*}$ & $1.0,1.4$ \\
\hline Zimbabwe & 2015 & 1.0 & $0.8,1.3$ & 1.2 & $0.9,1.4$ & 1.0 & $0.8,1.3$ & 1.2 & $0.9,1.4$ & $1.4^{* *}$ & $1.1,1.7$ & $1.3^{*}$ & $1.0,1.6$ \\
\hline
\end{tabular}

CI - confidence interval, AOR - adjusted odds ratio

" $P<0.05$

" $P<0.01$

**:* $P<0.001$ 


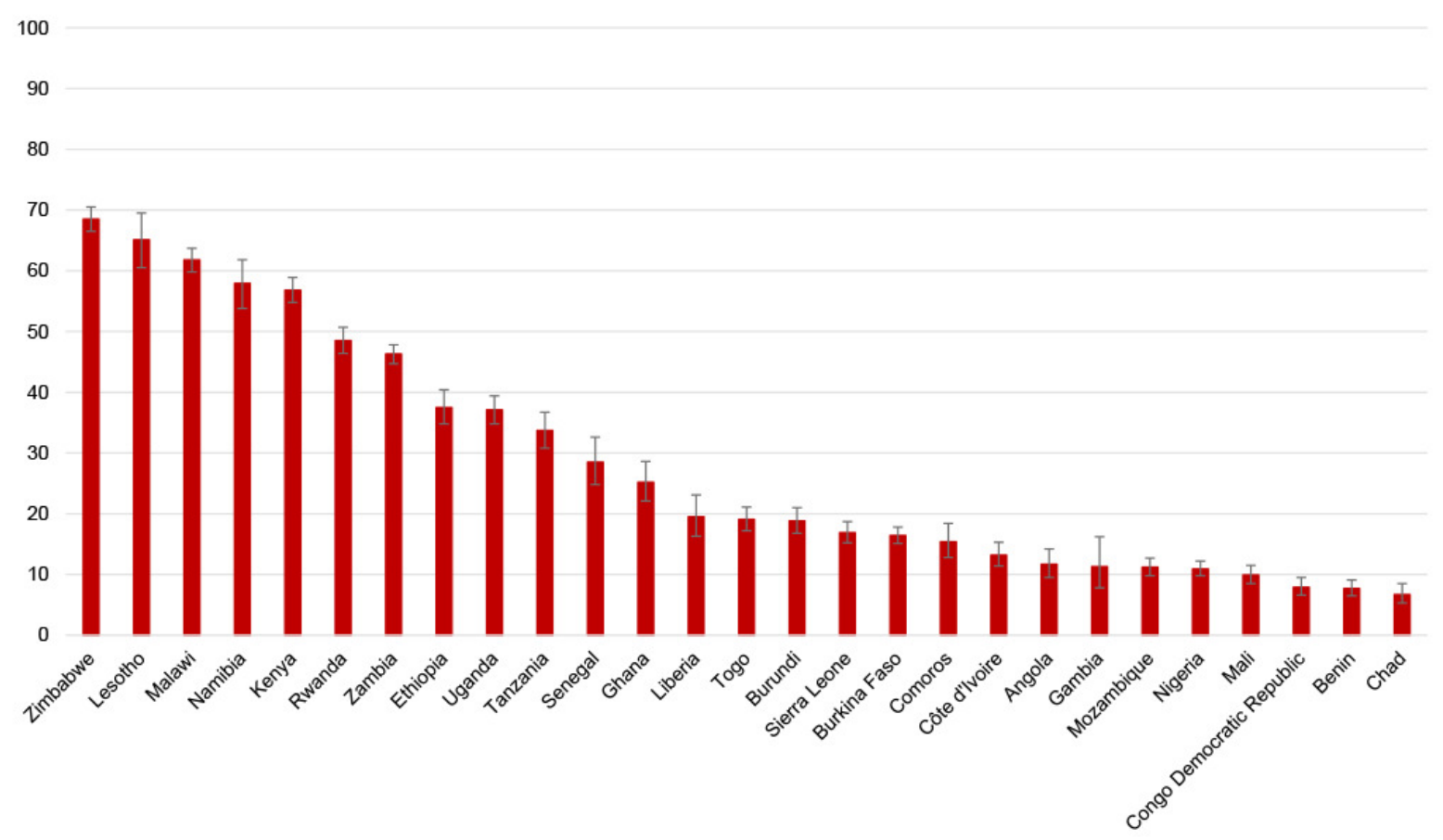

Figure 1. Percentage of women age 15-49 currently using a modern contraceptive method.

pared with women with partners that did not discuss. These countries were Burkina Faso, Burundi, Chad, Comoros, Democratic Republic of Congo, Côte d'Ivoire, Ghana, Liberia, Rwanda, Togo, Zambia, and Zimbabwe. No countries were significant in the opposite of the expected direction.

Figure 6 presents a summary of the results by dividing the countries into two mCPR groups; Group 1 are countries with a mCPR above $20 \%$ and Group 2 are countries with a mCPR below or equal to $20 \%$. The figure shows which countries were significant for each independent variable positive sign next to the country indicates that the odds ratio was above 1 and therefore in the expected direction, while countries with a negative sign and also in red indicates that the odds ratio was less than one and in the opposite of the expected direction.

When we compare the two mCPR groups, we see that except for the knowledge variable, group 2 had more significant findings than group 1. In addition all the results in group 2 were in the expected direction while there are two countries in group 1 that are in the opposite of the expected direction.

The behavior of men discussing family planning with a health worker in the last few months was a significant predictor of modern contraceptive use in the most countries compared with any other involvement variable. This was followed by women's education. In both cases, there were more significant countries in group 2 compared to group 1. In addition, there were more significant findings for women's education compared to men's education. For the two men's attitudes related to family planning, the attitude that women who use contraception may become promiscuous was a significant predictor of modern contraceptive use in more countries than was the attitude that contraception is only women's business. Only Nigeria showed significance in the expected direction for both of the attitude variables with modern contraceptive use. Knowledge of women's fertile period was the weakest predictor of modern contraceptive use, with only two countries showing significance one of while was in the opposite direction.

\section{DISCUSSION}

The analysis used DHS data from 27 sub-Saharan African countries to examine whether a partner's involvement in their wife's family planning can have an effect on her modern contraceptive use. The men's questionnaire in these surveys asked men questions related to their knowledge, attitude, and behavior on contraception. The men's and women's education level was also examined. The main finding was that men's behaviors and women's education level showed the most significant findings.

In general, few countries exhibited significant findings as summarized in Figure 6, and for two countries the significant findings were in the opposite of the expected direction. The lack of significance found in some of the involvement variables could be due to the nature of the survey question. For some variables, there is a direct link between the question and the outcome, such as men discussing family planning with a health worker in the last few months and current modern contraceptive use by their partners. For others, such as having correct knowledge of a woman's fertile period, the link with modern contraceptive use is not direct and therefore weaker. Only one country, Sierra Leone showed that women were more likely to use modern contraception if their partners had correct knowledge compared to women with partners that had incorrect knowledge. For Namibia, the finding was in the opposite of the expected direction. Questions directly related to men's knowledge on 
A)

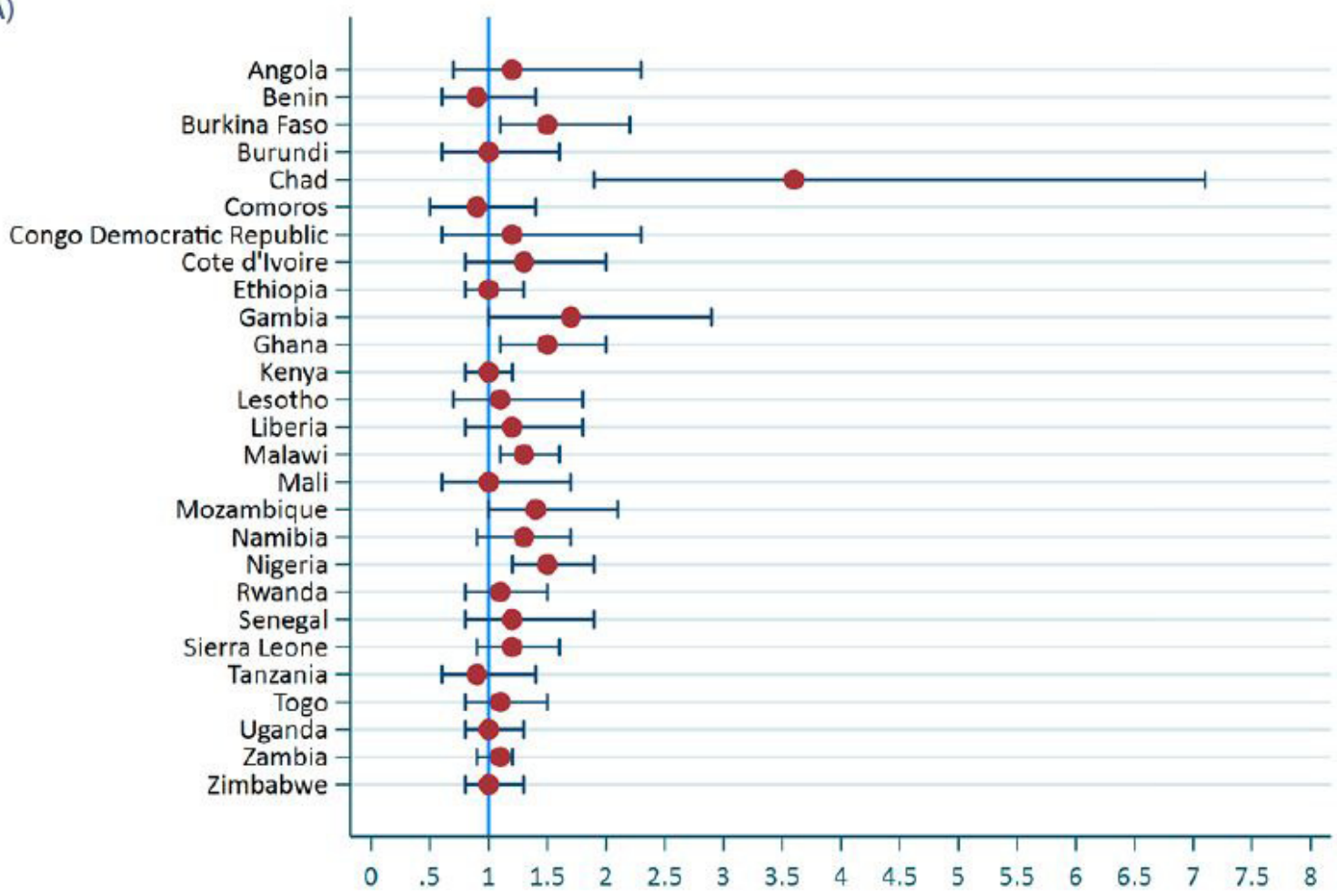

B)

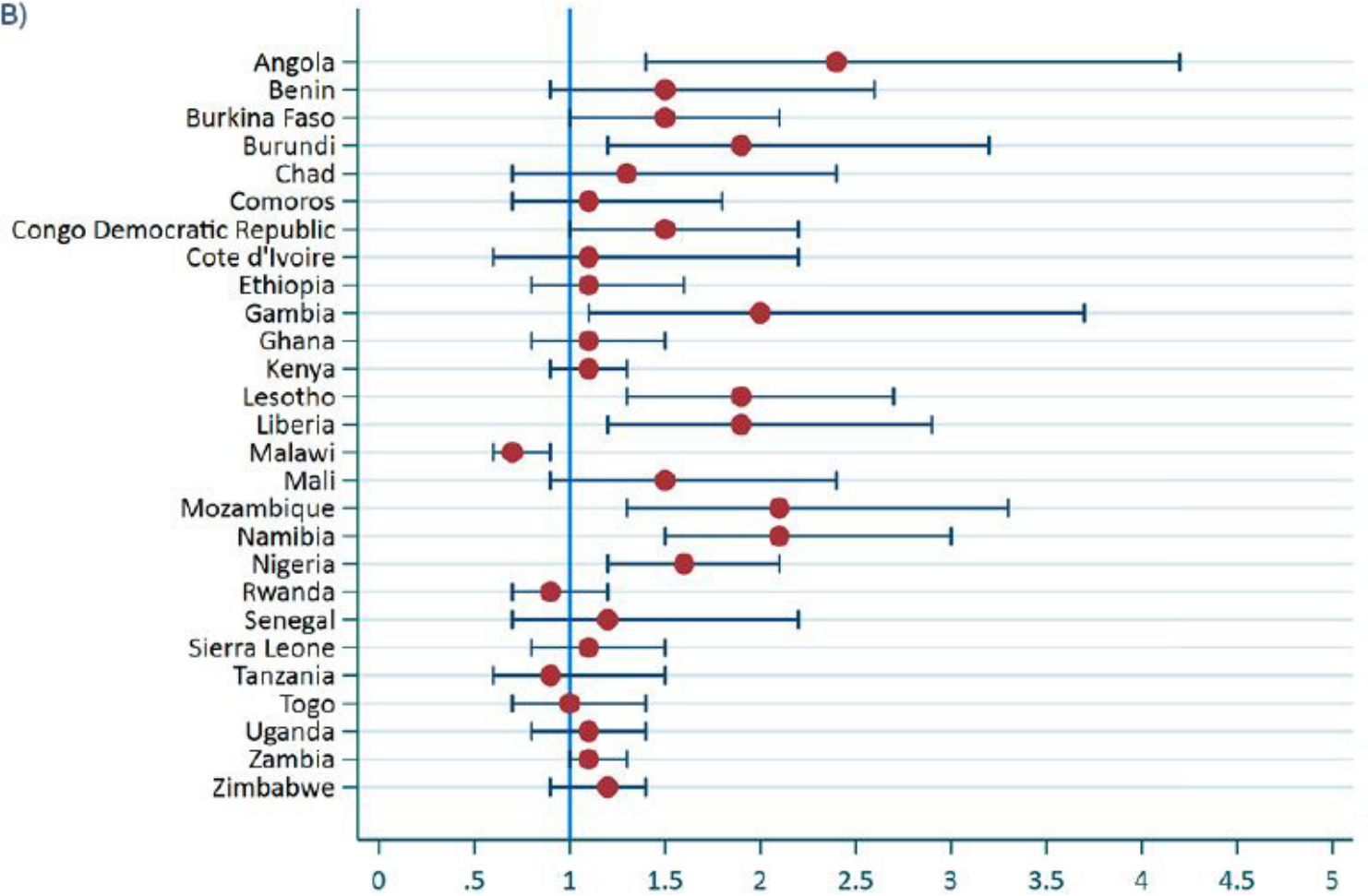

Figure 2. Adjusted odds ratios for modern contraceptive use by men's and women's education level.

Panel A. Adjusted odds ratios of men with secondary or above education compared to men with no or primary level education. Panel B. Adjusted odds ratios of women with secondary or above education compared to men with no or primary level education. 


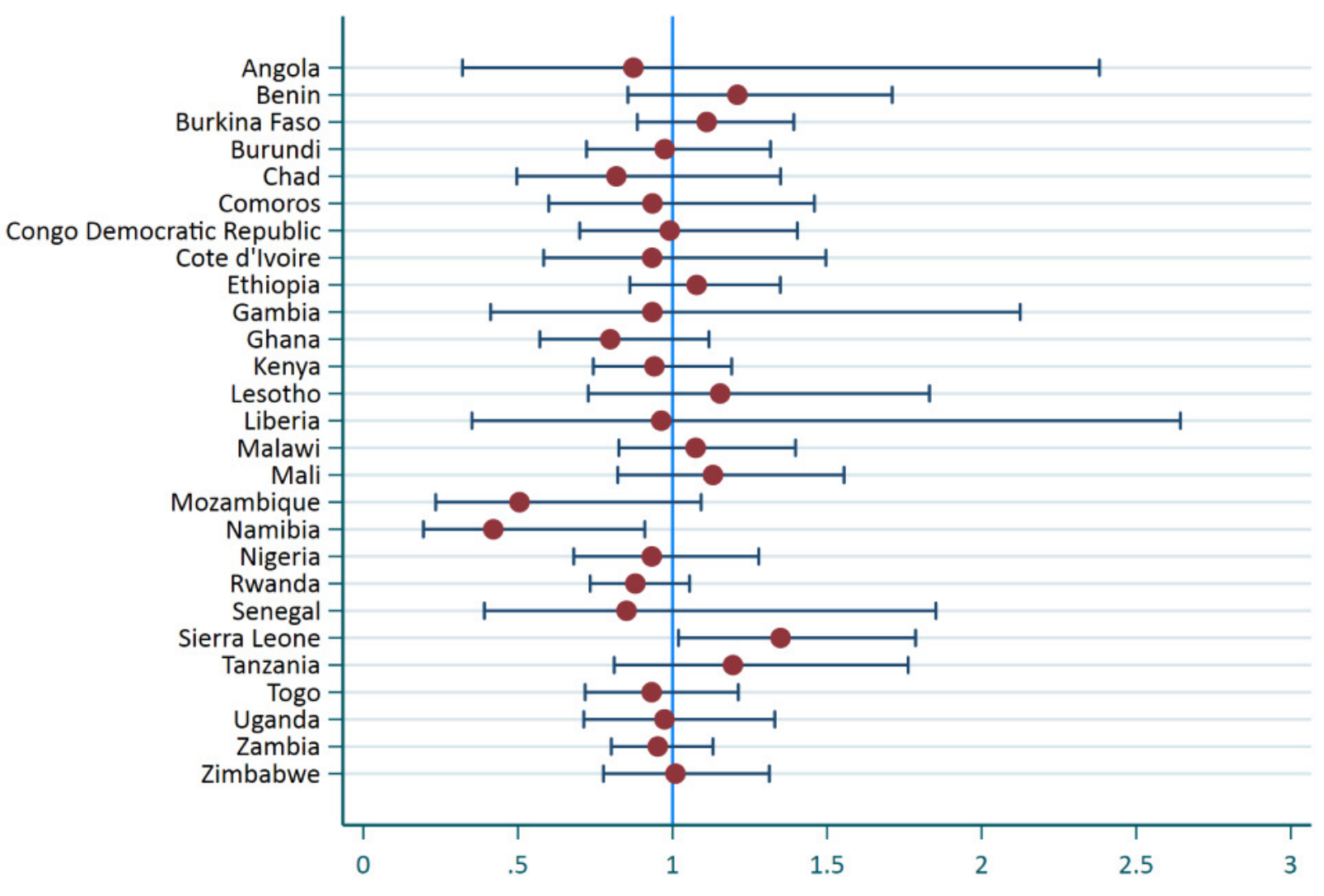

Figure 3. Adjusted odds ratios for modern contraceptive use of men's correct knowledge of the fertile period compared with men with incorrect knowledge.

modern contraceptive use would have been more appropriate for the analysis than the question on knowledge of the fertile period. However, such questions were not available in the DHS Men's Questionnaire.

The summary in Figure 6 shows that the behavior of men discussing family planning with a health worker in the last few months is a significant predictor of modern contraceptive use in more countries than for any other men's involvement variable (significant in 12 countries, all in the expected direction). Other studies have also found that men who participated in male-only or couples counseling sessions with health care providers were more likely to report using modern contraception as a couple compared with men who did not participate in such sessions. $8,19,20$ However, these studies are prospective case-control studies which compare an intervention group that had the discussions or education on family planning compared to a control group. The DHS data is cross-sectional and this is one of the main limitations in the analysis and specifically for this behavior variable. With the DHS data, we cannot directly measure the impact of discussion with the health worker, which could have happened before or perhaps after the women began using a contraceptive method.

This limitation would also mean that women (whether themselves or their partner) who are already using a mod- ern contraceptive method might not need to discuss family planning with a health worker. In that case, however, we would have expected to see some significance in the opposite of the expected direction, since those who did not discuss family planning would be more likely to be already using modern contraception. However, this was not the case in the analysis, as none of the countries were significant in the opposite of the expected direction, indicating that the timing between the variables is not a major limitation. The quality of the discussion with the health worker could also be factor for not observing more significant findings. If the quality of the discussion or counseling was poor, this could have a negative impact on the likelihood of using a modern method. Several studies have shown that good quality of counseling in family planning can increase the likelihood of contraceptive use and continuation. ${ }^{20-24}$ However, these studies only looked at counseling provided to women. The DHS does not collect data from respondents on the quality of the counseling or the satisfaction level of the discussion with the health care worker. Therefore, this information could not be included in the analysis.

The results have also shown that for this behavior variable, more significant findings were observed for countries that have a mCPR of less than or equal to $20 \%$ (8 countries) compared to countries with a mCPR more than 20\% (4 
A)

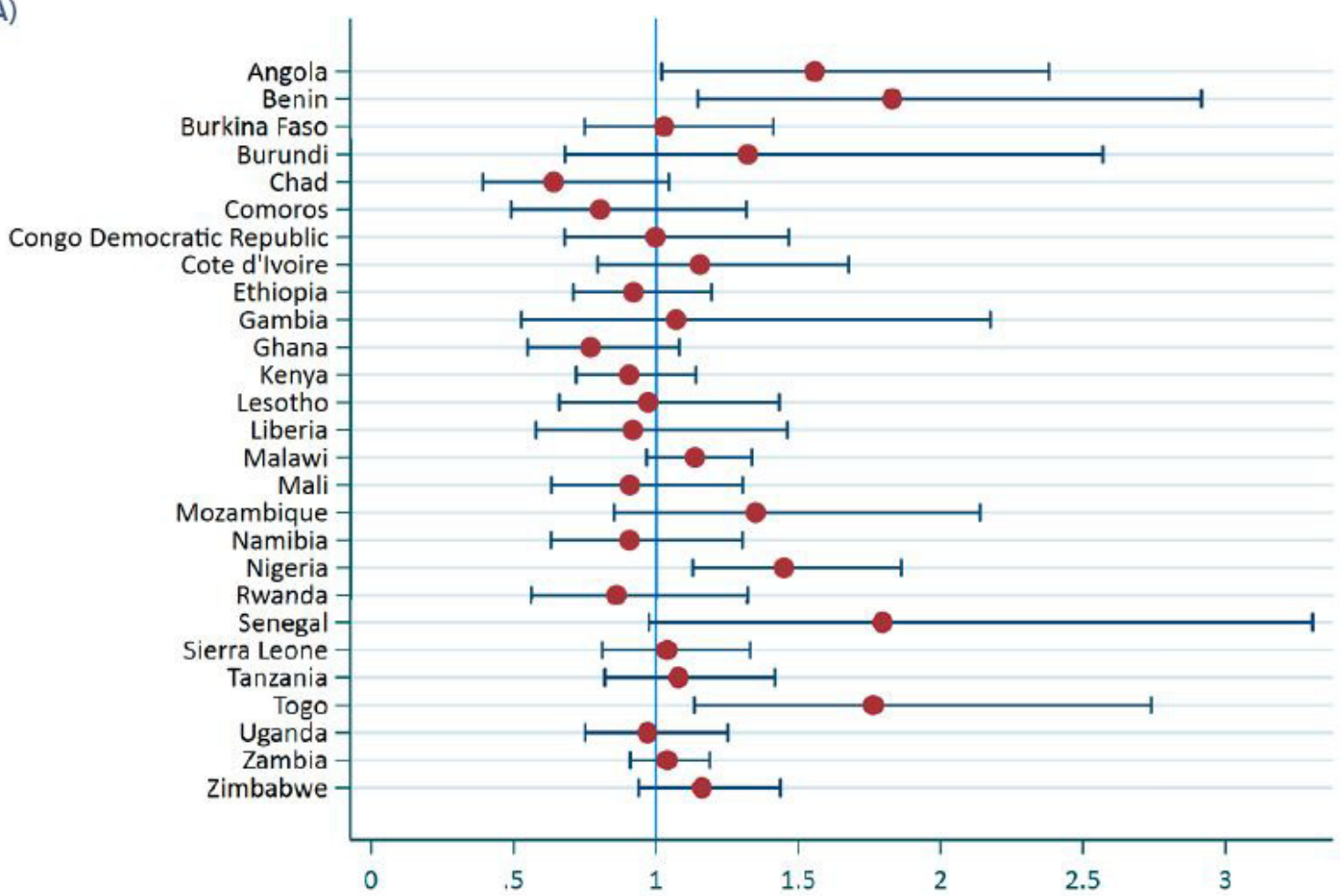

B)

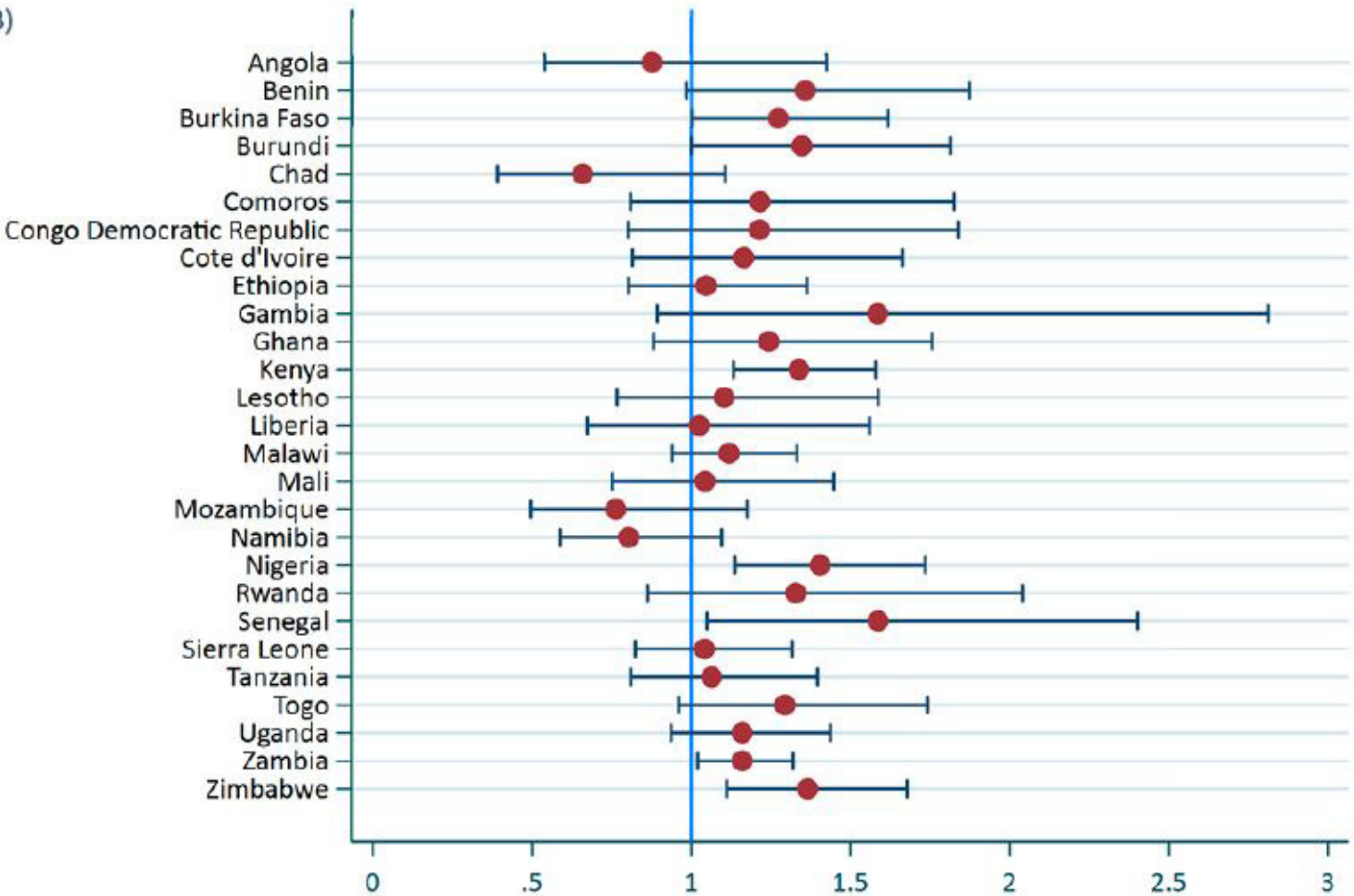

Figure 4. Adjusted odds ratios for modern contraceptive use by men's attitudes toward contraceptive use.

Panel A. Adjusted odds ratios of men who do not agree that contraception is a woman's business compared with men who do agree. Panel B. Adjusted odds ratios of men who do not agree that contraception is a might make a woman promiscuous compared with men who do agree. 


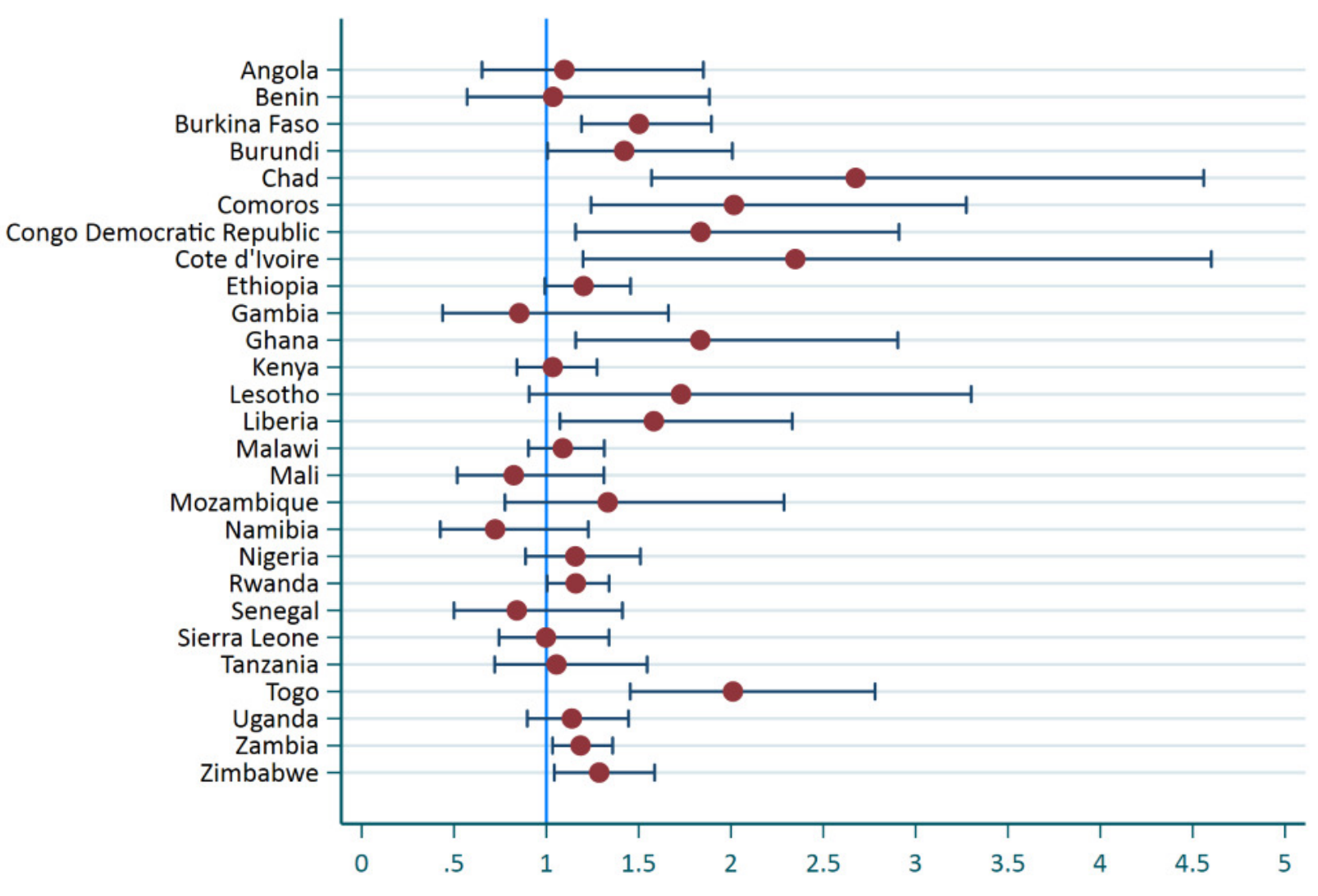

Figure 5. Adjusted odds ratios for modern contraceptive use of men who discussed family planning with a health worker compared with men who did not.

countries). There is also a great difference in the number of significant countries between the two mCPR groups for the findings relation to women's education. Eight countries with a mCPR of less than or equal to $20 \%$ showed a significance in the expected direction for women with secondary or above education compared to none or primary education. This is compared to 3 countries with significant results that have a mCPR of more than $20 \%$ (one country, Malawi, was in the opposite of the expected direction). From an intervention perspective, this could mean that countries with lower mCPR have more room for change than countries with higher $\mathrm{MCPR}$ and interventions such as education for women, and providing and improving health worker discussions on modern contraceptive use for women and their partners can be more effective in low mCPR countries.

Few patterns arose for the attitude variables. There were more significant findings for the attitude variables compared to the knowledge variable, but less than the behavior variable. There were also more significant findings for the attitude of agreeing that a women who uses contraception may become more promiscuous compared to the attitude of contraception is only a women's business.

\section{CONCLUSIONS}

Although there were many countries that did not show significance, especially for the knowledge and attitude variables, our findings highlight the importance of men being involved in family planning by actively discussing family planning with a health care worker. While behavior is critical, several studies have noted that interventions that focus on all three aspects of knowledge, attitude and behavior result in better overall family planning outcomes. ${ }^{8,25,26}$ Findings also highlight the importance of women's level of education in the use of modern contraceptives. However, other studies have noted to achieve universal access to family planning, efforts that promote women's education should be paired with improving financial, cultural and geographical access to modern contraceptives. ${ }^{27-29}$ Other studies have also highlighted the importance of spousal communication in increasing the use of modern contraceptives. ${ }^{30,31}$ Qualitative studies and in-depth country-specific analysis are also needed to understand these country-specific findings and whether cultural factors could explain the differences between countries; for instance, why some countries are showing significance in the opposite of the expected direction, or why some countries are showing significant findings while others are not. 


\begin{tabular}{|c|c|c|}
\hline & $\begin{array}{c}\text { Group1 } \\
\mathrm{mCPR}>20 \% \\
\end{array}$ & $\begin{array}{c}\text { Group } 2 \\
\mathrm{mCPR} \leq 20 \% \\
\end{array}$ \\
\hline \multicolumn{3}{|l|}{ Education } \\
\hline $\begin{array}{l}\text { Men's education is secondary or } \\
\text { above (compared to none/primary) }\end{array}$ & $\begin{array}{l}\text { Ghana + } \\
\text { Malawi + }\end{array}$ & $\begin{array}{c}\text { Burkina Faso + } \\
\text { Chad }+ \\
\text { Nigeria }+\end{array}$ \\
\hline $\begin{array}{l}\text { Woman's education is secondary or } \\
\text { above (compared to none/primary) }\end{array}$ & $\begin{array}{c}\text { Lesotho + } \\
\text { Namibia + } \\
\text { Malawi - }\end{array}$ & $\begin{array}{c}\text { Angola + } \\
\text { Burkina Faso + } \\
\text { Burundi + } \\
\text { Congo DR + } \\
\text { Gambia + } \\
\text { Liberia + } \\
\text { Mozambique + } \\
\text { Nigeria + }\end{array}$ \\
\hline \multicolumn{3}{|l|}{ Knowledge } \\
\hline $\begin{array}{l}\text { Have correct knowledge of women's } \\
\text { fertile period (compared with incorrect } \\
\text { knowledge) }\end{array}$ & Namibia - & Sierra Leone + \\
\hline \multicolumn{3}{|l|}{ Attitudes } \\
\hline $\begin{array}{l}\text { Does not agree that contraception is } \\
\text { only women's business (compared } \\
\text { with agree) }\end{array}$ & & $\begin{array}{c}\text { Angola + } \\
\text { Benin + } \\
\text { Nigeria + } \\
\text { Togo + }\end{array}$ \\
\hline $\begin{array}{l}\text { Does not agree that women who use } \\
\text { contraception may become } \\
\text { promiscuous (compared with agree) }\end{array}$ & $\begin{array}{c}\text { Senegal + } \\
\text { Zambia + } \\
\text { Zimbabwe + }\end{array}$ & $\begin{array}{c}\text { Burkina Faso + } \\
\text { Burundi + } \\
\text { Kenya + } \\
\text { Nigeria + }\end{array}$ \\
\hline \multicolumn{3}{|l|}{ Behavior } \\
\hline $\begin{array}{l}\text { Discussed family planning with health } \\
\text { worker in the last few months } \\
\text { (compared with did not discuss) }\end{array}$ & $\begin{array}{c}\text { Ghana + } \\
\text { Rwanda + } \\
\text { Zambia + } \\
\text { Zimbabwe + }\end{array}$ & $\begin{array}{c}\text { Burkina Faso + } \\
\text { Burundi + } \\
\text { Chad + } \\
\text { Comoros + } \\
\text { Congo DR + } \\
\text { Côte d'lvoire + } \\
\text { Liberia + } \\
\text { Togo + }\end{array}$ \\
\hline
\end{tabular}

Figure 6. Summary of significant findings from all the regression models by modern contraceptive prevalence rate groups.

\section{COMPETING INTERESTS}

\section{ACKNOWLEDGEMENTS}

The authors wish to thank Tim Shand, Christopher Hook, and Joy Fishel for their comments provided on an earlier and broader version of the research from which this paper originated. The views expressed in this submitted article are not an official positon of ICF or USAID.

\section{FUNDING}

USAID.
The authors completed the Unified Competing Interest form at http://www.icmje.org/coi_disclosure.pdf (available upon request from the corresponding author), and declare no conflicts of interest.

\section{CORRESPONDENCE TO:}

Shireen Assaf M.S., Ph.D. 530 Gaither Road

Suite 500

Rockville, MD, 20850

USA

shireen.assaf@icf.com 


\section{REFERENCES}

1. Gallen ME, Liskin L, Kak N. Men--new focus for family planning programs. Popul Rep J: Family Planning Programs. 1986;33:J889-919.

2. Green CP, Cohen SI, Belhadj-El Ghouayel H. Male Involvement in Reproductive Health Including Family Planning and Sexual Health. United Nations Population Fund; 1995. Accessed August 25, 2018. htt ps://www.popline.org/node/295292

3. Ackerson K, Zielinski R. Factors influencing use of family planning in women living in crisis affected areas of Sub-Saharan Africa: A review of the literature. Midwifery. 2017;54:35-60. doi:10.1016/i.mi dw.2017.07.021

4. Vouking MZ, Evina CD, Tadenfok CN. Male involvement in family planning decision making in sub-Saharan Africa- what the evidence suggests. Pan Afr Med J. 2014;19:349. doi:10.11604/pamj.2014.19.34 $\underline{9.5090}$

5. Barker G, Ricardo C, Nascimento M. Engaging Men and Boys in Changing Gender-Based Inequity in Health: Evidence from Programme Interventions. World Health Organization; 2007. Accessed August 25, 2018. htt p://www.who.int/gender/documents/Engaging_men_b oys.pdf

6. Kraft JM, Wilkins KG, Morales GJ, Widyono M, Middlestadt SE. An evidence review of genderintegrated interventions in reproductive and maternal-child health. J Health Commun. 2014;19(Suppl 1):122-141. doi:10.1080/10810730.201 $\underline{4.918216}$

7. Mkandawire E, Hendriks SL. A qualitative analysis of men's involvement in maternal and child health as a policy intervention in rural Central Malawi. $B M C$ Pregnancy Childbirth. 2018;18(1):31. doi:10.1186/s128 84-018-1669-5

8. Shattuck D, Kerner B, Gilles K, Hartmann M, Ng'ombe T, Guest G. Encouraging contraceptive uptake by motivating men to communicate about family planning: the Malawi Male Motivator project. Am J Public Health. 2011;101(6):1089-1095. doi:10.21 05/ajph.2010.300091

9. Okigbo CC, Speizer IS, Corroon M, Gueye A. Exposure to family planning messages and modern contraceptive use among men in urban Kenya, Nigeria, and Senegal: a cross-sectional study. Reprod Health. 2015;12:63. doi:10.1186/s12978-015-0056-1
10. Duze MC, Mohammed IZ. Male knowledge, attitude, and family planning practices in Northern Nigeria. Afr J Reprod Health. 2006;10(3):53-65. doi:1 $\underline{0.2307 / 30032471}$

11. MacQuarrie KLD, Edmeades J, Steinhaus M, Head SK. Men and Contraception: Trends in Attitudes and Use. ICF International; 2015.

12. Ezeanolue EE, Iwelunmor J, Asaolu I, et al. Impact of male partner's awareness and support for contraceptives on female intent to use contraceptives in southeast Nigeria. BMC Public Health. 2015;15:879. doi:10.1186/s12889-015-2216-1

13. Terefe A, Larson CP. Modern contraception use in Ethiopia: does involving husbands make a difference? Am J Public Health. 1993;83(11):1567-1571. doi:10.210 5/ajph.83.11.1567

14. Kabagenyi A, Jennings L, Reid A, Nalwadda G, Ntozi J, Atuyambe L. Barriers to male involvement in contraceptive uptake and reproductive health services: a qualitative study of men and women's perceptions in two rural districts in Uganda. Reprod Health. 2014;11:21. doi:10.1186/1742-4755-11-21

15. Koffi TB, Weidert K, Bitasse EO, et al. Engaging Men in Family Planning: Perspectives From Married Men in Lomé, Togo. Glob Health Sci Pract. 2018;6(2):317-329. doi:10.9745/ghsp-d-17-00471

16. Doyle K, Levtov RG, Barker G, et al. Gendertransformative Bandebereho couples' intervention to promote male engagement in reproductive and maternal health and violence prevention in Rwanda: findings from a randomized controlled trial. PLoS One. 2018;13(4):e0192756. doi:10.1371/journal.pon e.0192756

17. Health Communication Capacity Collaborative (Hc3). Gender Transformative Approaches. Published 2014. Accessed August 25, 2018. https://sbccimpleme ntationkits.org/demandrmnch/ikitresources/gender-t ransformative-approaches-2/

18. Barker G, Ricardo C, Nascimento M, Olukoya A, Santos C. Questioning gender norms with men to improve health outcomes: Evidence of impact. Glob Public Health. 2010;5(5):539-553. doi:10.1080/174416 90902942464

19. Tilahun T, Coene G, Temmerman M, Degomme O. Couple based family planning education: changes in male involvement and contraceptive use among married couples in Jimma Zone, Ethiopia. BMC Public Health. 2015;15:682. doi:10.1186/s12889-015-2057-y 
20. Daniele MA, Ganaba R, Sarrassat S, et al. Involving male partners in maternity care in Burkina Faso: a randomized controlled trial. Bull World Health Organ. 2018;96(7):450-461. doi:10.2471/blt.17.206466

21. Abdel-Tawab N, Roter D. The relevance of clientcentered communication to family planning settings in developing countries: lessons from the Egyptian experience. Soc Sci Med. 2002;54(9):1357-1368. doi:1 $\underline{0.1016 / \mathrm{s} 0277-9536(01) 00101-0}$

22. Dehlendorf C, Henderson JT, Vittinghoff E, et al. Association of the quality of interpersonal care during family planning counseling with contraceptive use. Am J Obstet Gynecol. 2016;215:78.e1-9. doi:10.10 16/j.ajog.2016.01.173

23. Kamhawi S, Underwood C, Murad H, Jabre B. Client-centered counseling improves client satisfaction with family planning visits: evidence from Irbid, Jordan. Glob Health Sci Pract. 2013;1(2):180-192. doi:10.9745/ghsp-d-12-00051

24. Lee JK, Parisi SM, Akers AY, Borrerro S, Schwarz EB. The impact of contraceptive counseling in primary care on contraceptive use. J Gen Intern Med. 2011;26(7):731-736. doi:10.1007/s11606-011-1647-3

25. Increasing Men's Engagement to Improve Family Planning Programs in South Asia. FHI 360; 2012. Accessed August 25, 2018. https://www.fhi360.org/sit es/default/files/media/documents/MaleEngageBrief.p df
26. High Impact Practices in Family Planning (HIPs). Engaging Men and Boys in Family Planning: A Strategic Planning Guide. USAID; 2018. Accessed August 25, 2018. https://www.fphighimpactpractices.org/guides/ engaging-men-and-boys-in-family-planning

27. Emina JBO, Chirwa T, Kandala NB. Trend in the use of modern contraception in sub-Saharan Africa: does women's education matter? Contraception. 2014;90(2):154-161. doi:10.1016/j.contraception.201 $\underline{4.02 .001}$

28. Feyisetan B, Casterline JB. Socio-economic status fertility preferences and contraceptive change in subSaharan Africa. Afr Popul Studies. 2000;15:1-24.

29. Garenne M. Education and Fertility in Sub-Saharan Africa: A Longitudinal Perspective. ICF International; 2012.

30. Link CF. Spousal communication and contraceptive use in rural Nepal: an event history analysis. Stud Fam Plann. 2011;42(2):83-92. doi:10.11 11/j.1728-4465.2011.00268.x

31. Oluwole E, Kuyinu Y, Goodman O, Odugbemi B, Akinyinka M. Factors Influencing the Uptake of Modern Family Planning Methods among Women of Reproductive Age in A Rural Community in Lagos State. Int J Trop Dis Health. 2016;11(3):1-11. doi:10.97 34/ijtdh/2016/20373 


\section{SUPPLEMENTARY MATERIALS}

\section{Online Supplementary Document}

Download: https://www.joghr.org/article/12029-women-s-modern-contraceptive-use-in-sub-saharan-africa-doesmen-s-involvement-matter/attachment/29755.pdf 